\title{
Deposition of Platinum from Bis(Acetylacetonato)Platinum(II)
}

\author{
J. Arndt, L. Klippe, R. Stolle and G. Wahl \\ Institut für Oberflächentechnik und Plasmatechnische Werkstoffentwicklung, Technische Universität \\ Braunschweig, Bienroder Weg 53, 38108 Braunschweig, Germany
}

\begin{abstract}
The evaporation and deposition process of Bis(acetylacetonato)platinum(II) ( $\mathrm{Pt}(\mathrm{acac})_{2}$ ) was examined in a computerized microbalance system, which allows the measuring of the mass of evaporating precursor and depositing layer simultaneously.

The investigations were carried out in an argon-atmosphere and an argon/oxygen-atmosphere with pressure ranging from $250 \mathrm{~Pa}$ to $1000 \mathrm{~Pa}$. The deposition kinetics were investigated in the temperature range between $\mathrm{T}_{\text {dep }}$ $=523 \mathrm{~K}$ and $T_{d c p}=733 \mathrm{~K}$. A strong dependence of the deposition rate on the pretreatment of the substrate was observed. Beginning the deposition on alumina with low deposition temperatures $\mathrm{T}_{\mathrm{dep}}$ an activation energy of 204 $\pm 9 \mathrm{~kJ} / \mathrm{mol}$ was found. On platinum precoated substrates we observed higher deposition rates and lower values for the activation energy, if the precoating was carried out at temperature $T_{\text {pre }}>T_{\text {dep }}$. At long deposition times with $T_{\text {dep }}=$ const. the deposition rates on precoated substrates decreased to the values obtained without precoating at higher temperatures. This effect has not been clarified.

In argon-atmosphere platimum layers containing carbon were deposited. Increasing the deposition temperature caused increased carbon contamination. The carbon can be removed by oxidation in air after the deposition. Platinum coatings without carbon contamination were obtained by adding oxygen during the deposition process.
\end{abstract}

\section{Introduction}

Thin films of platinum are used in many applications, for example as electrical contacts in semiconductor devices, as coatings for high temperature crucibles, as diffusion barrier metallization or as catalysts in chemical processes.

MOCVD is a well-established technique for preparing thin films offering many advantages such as low deposition temperature, relatively simple equipment and high throwing power. For the MOCVD of platinum several volatile metalorganic compounds were investigated in the literature. One of them is $\mathrm{Pt}(\mathrm{acac})_{2}$, a reasonably priced, air-stable yellow powder, which is simple to handle. This is preferred in technical processes rather than other expensive, air and moisture sensitive precursor substances, for example Cyclopentadienyltrimethylplatinum [1].

First Marboe [2] described the deposition of platinum using $\mathrm{Pt}(\mathrm{acac})_{2}$. Further studies were made by Rand [3]. They found, that platinum layers deposited from $\mathrm{Pt}(\mathrm{acac})_{2}$ contain carbon, which disqualifies them for microelectronical applications. After removing the carbon by oxidation, the platinum layers deposited from $\mathrm{Pt}(\mathrm{acac})_{2}$ revealed no sufficient electrical conductivity. Ceramics coated with platinum from $\mathrm{Pt}(\mathrm{acac})_{2}$ are supposed to be used as catalysts, assuming that the codeposited carbon does not affect the catalytic activity. In this study we investigated the deposition of platinum on polycrystalline alumina in argon- and argon/oxygenatmosphere. 
Supporting ceramic materials used for catalysts in chemical processes are of various shapes, c.g. long lubes. Therefore the deposition kinetics must be well known to optimize the lhowing power of the CVD-process and prepare uniform platinum films on substrates with different geometries. So far no detailed investigation about the kinetics of evaporation and deposition of $\mathrm{Pl}(\mathrm{acac})_{2}$ has been published.

The evaporation and deposition process were examined in a computerized microbalance system. which allows measuring the mass of evalporating precursor and deposited layer sinultaneously.

\section{Experimental}

A schematic diagram of the microbalance system is shown in Fig. L. Evaporation vessel and substrate were connected with magnetic suspension balances. The balance signals were monitored by a computer, which also recorded all process readings as temperatures, total gas pressure and flow rates. All gas flow rates were adjusted by mass flow controllers.

The geometry of the evaporator shown in Fig.2 was described earlier by Pulver et al. [4]. $\mathrm{Pl}(\text { acac })_{2}$ was supplied by Degussa AG. Evaporation experiments were carried out between $T_{c y}=413 \mathrm{~K}$ and $T_{c v}=453 \mathrm{~K}$. Argon was used as carrier gas with a flow rate of 5 $l_{N} / h$. The reactor is depicted schematically in Fig.3. The polycrystalline alumina substrates (20 $\mathrm{mm} \times 20 \mathrm{~mm} \times 0.5 \mathrm{~mm}$ ) were altached to the balance with a $\mathrm{NiCr}$-wire $(\varnothing=0.05 \mathrm{~mm})$. The deposition temperalure ranged from $\mathrm{T}_{\text {dep }}=$ $52.3 \mathrm{~K}$ to $\mathrm{T}_{\mathrm{dcp}}=73.3 \mathrm{~K}$. The investigations were carried out in argon-atmosphere and argon/oxygen-almosphere with pressure ranging from $250 \mathrm{~Pa}$ to $1000 \mathrm{~Pa}$. The total argon carrier gas flow was $9.5 \quad \mathrm{I}_{\mathrm{N}} / \mathrm{h}$. The deposition experiments in argon/oxygenatmosphere were made at a total gas pressure ptolal of $1000 \mathrm{~Pa}$ by adding oxygen through a nozzle $10 \mathrm{~cm}$ in front of the reactor (Fig. 1 ). The oxygen flow rates were $0.121_{N} / \mathrm{h}$ and 0.3 $I_{N} / h$ corresponding to oxygen partial pressures Poxygen of $11 \mathrm{~Pa}$ and $29 \mathrm{~Pa}$. The given rates of evalporation and deposition were calculated from the slope in the plot weight vs. time, which was recorded at constant conditions over a period of 30 minutes.

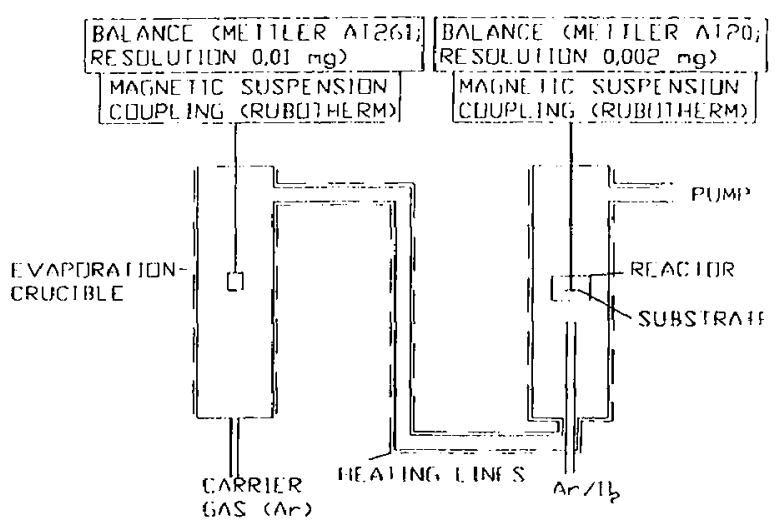

Fig. 1. Schematic diagram of the nicrobalance system

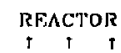

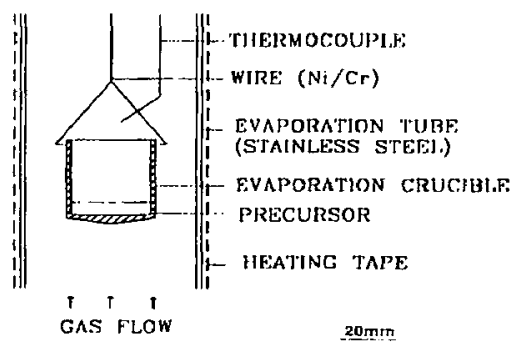

Fig. 2. Geometry of the evaporator

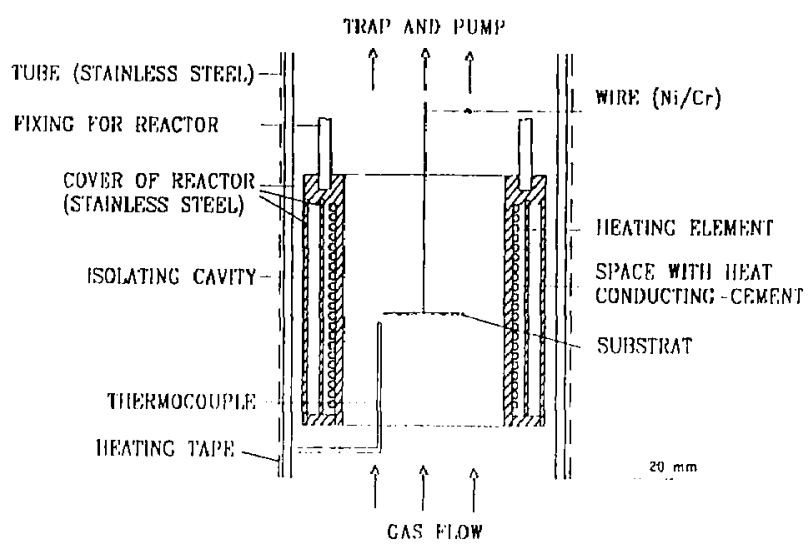

Fig. 3. Geometry of the reactor 
Platinum films were prepared in argonatmosphere at temperatures of $\mathrm{T}_{\text {dep }}=653 \mathrm{~K}$, $673 \mathrm{~K}, 703 \mathrm{~K}$ and $723 \mathrm{~K}\left(\mathrm{p}_{\text {total }}=1000 \mathrm{~Pa}\right)$. Additionally a platinum film was deposited in an argon/oxygen-atmosphere at $\mathrm{T}_{\text {dep }}=618 \mathrm{~K}$ $\left(p_{\text {total }}=1000 \mathrm{~Pa}, p_{\text {oxygen }}=29 \mathrm{~Pa}\right)$. The relative carbon content was measured with WDX. The absolute carbon content was determined by measuring the weight decrease of the sample generated by oxidation of the carbon in air. The crystal structure of the films was studied with XRD. The surface morphology was examined by SEM and AFM.

\section{Results and Discussion}

\subsection{Evaporation of $\mathrm{Pt}(\mathbf{a c a c})_{2}$}

In Fig.4 the evaporation rates are plotted vs. the reciprocal temperature. The activation energy for evaporation was determined to be $113 \pm 5 \mathrm{~kJ} / \mathrm{mol}$. The evaporation rate is as expected proportional to the reciprocal total pressure [5]. By raising the gas flow from $5 \mathrm{l}_{\mathrm{N}} / \mathrm{h}$ to $15 \mathrm{I}_{\mathrm{N}} / \mathrm{h}$ the evaporation rate increased by approx. $6 \%$.

\subsection{Deposition of $\mathrm{Pt}(\mathrm{acac})_{2}$ in argon- atmosphere}

All deposition experiments were made with a total gas flow rate of $9.5 \mathrm{l}_{\mathrm{N}} / \mathrm{h}$. The dependence of the deposition rate on $\mathrm{Pt}(\mathrm{acac})_{2}$-partialpressure (Fig.5) was examined in the kinetics controlled regime at $\mathrm{T}_{\text {dep }}=658 \mathrm{~K}$ (see Fig.6). The total gas pressures were $250 \mathrm{~Pa}, 500 \mathrm{~Pa}$ and $1000 \mathrm{~Pa}$. The reaction kinetics is of first order and independent of the total pressure.

For the following analysis the reduced deposition rate $\mathrm{i}_{\text {red }}=\mathrm{j}_{\mathrm{dep}} / \mathrm{p}_{\mathrm{Pr}(\mathrm{acac})}$ was determined ( $\mathrm{j}_{\text {dep }}$ : deposition rate, $\mathrm{p}_{\text {h(incac): }}$ partial pressure of $\left.\mathrm{Pt}(\mathrm{acac})_{2}\right)$. The value $\mathrm{i}_{\text {red }}$ has the advantage, that it is independent of the partial pressure because of the linear concentration dependence (see Fig.5).

The deposition kinetics of $\mathrm{Pt}(\mathrm{acac})_{2}$ on alumina was investigated by increasing the temperature from $T_{\text {dep }}=653 \mathrm{~K}$ to $T_{\text {dep }}=723 \mathrm{~K}$ in steps of 5 $\mathrm{K}$. The temperature dependence of the deposition rate is recorded in Fig.6. Decreasing total gas pressure shifts the reduced deposition rates in the diffusion controlled regime to higher values because the reduced rate is

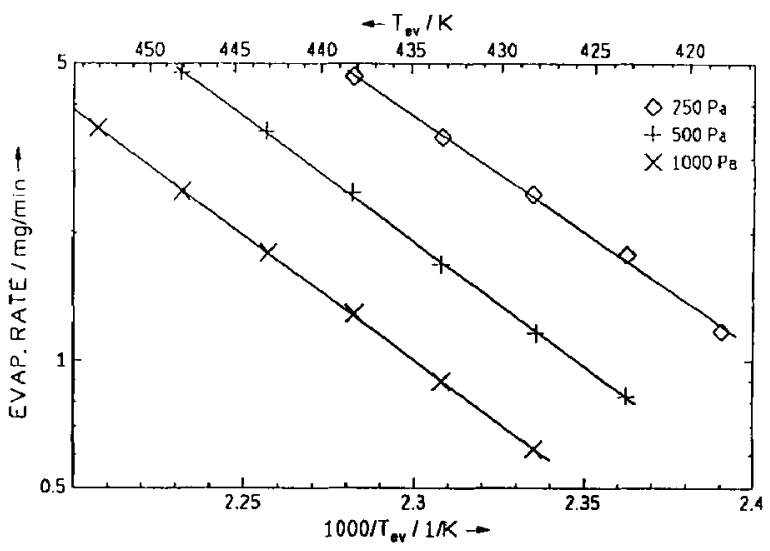

Fig. 4. Evaporation rate vs. $1000 / \mathrm{T}_{\mathrm{ev}}$

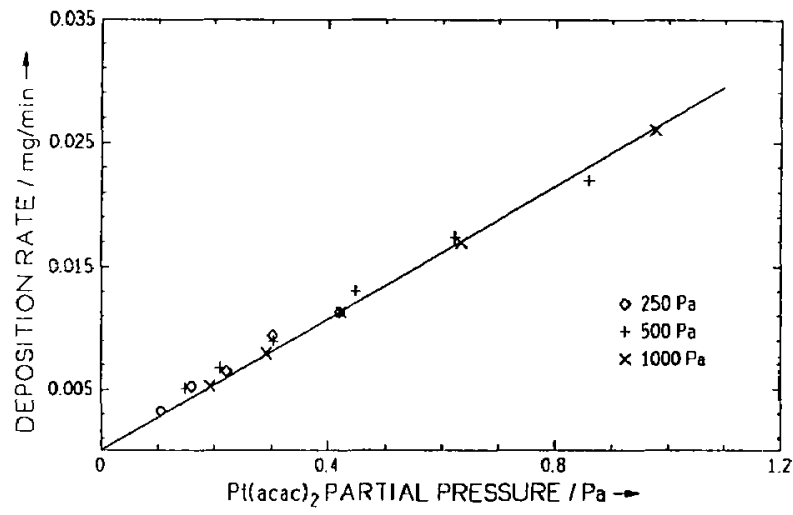

Fig. 5. Deposition rate vs. $\mathrm{Pt}(\mathrm{acac})_{2}$ partial pressure $\left(\mathrm{T}_{\text {dep }}=\right.$ $658 \mathrm{~K}$ )

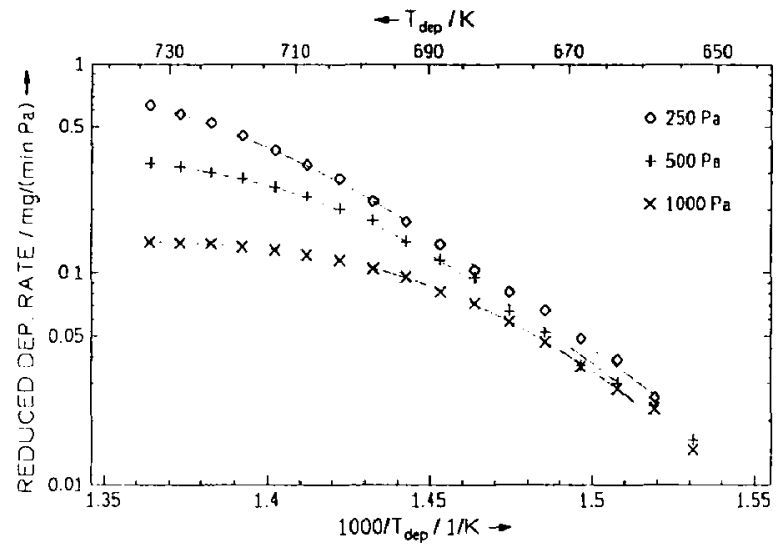

Fig. 6. Reduced deposition rate vs. reciprocal temperature 
proportional to $1 / \mathrm{p}_{\text {total }}$. This relation results from the fact, that at constant mole-fraction the deposition in the diffusion controlled range is independent of the total pressure [6].

The activation energy was determined to be $204 \pm 9 \mathrm{~kJ} / \mathrm{mol}$, independent of the total gas pressure.

In addition deposition experiments on platinum coated substrates were made. Our investigations have shown that the deposition rate on a precoated substrate depends on the preceding deposition temperature. After substrates were precoated with platinum at $T_{\text {pre }}$ $>T_{\text {dep }}$, the deposition rate at $T_{\text {dep }}$ was higher than the rates shown in Fig. 6.

To investigate this phenomenon, an alumina substrate was coated as described above (Fig.6). This means the final surface layer was deposited at $T_{\text {pre }}=723 \mathrm{~K}$. Afterwards the deposition temperature was decreased in steps of $15 \mathrm{~K}$ to $\mathrm{T}_{\text {dep }}=588 \mathrm{~K}$. The reduced deposition rates are shown in Fig.7. The activation energy for the decomposition reaction of $\mathrm{Pt}(\mathrm{acac})_{2}$ was determined to be $56 \pm$ $1 \mathrm{~kJ} / \mathrm{mol}$.

The deposition rate measured on a platinum precoated substrate at $T_{\text {dep }}=$ const. depends on the thickness of the film, which grows during the succeeding deposition process. At long deposition times the deposition rates always decreased to the values observed in Fig.6. This is shown in Fig.8. The deposition rate on a precoated substrate $\left(T_{\text {pre }}=723 \mathrm{~K}\right)$ was measured at $\mathrm{T}_{\text {dep }}=653 \mathrm{~K}$. The rates are plotted in Fig. 8 vs. the deposition mass. The deposition rate remains constant until the deposited mass reaches a value of approx. $6 \mathrm{mg}$ (corresponding to $0.35 \mu \mathrm{m}$ film thickness). Then the rate decreases continuously until the deposition rate reaches the value in Fig.6.

Because of this effect an experiment with a cyclic temperature sequence causes a hysteresis loop in the plot deposition rate vs. reciprocal temperature (Fig.9): Increasing temperature from $\mathrm{T}_{\text {dep }}=653 \mathrm{~K}$ to $\mathrm{T}_{\text {dep }}=723 \mathrm{~K}$ in steps of $10 \mathrm{~K}$ (branch I in Fig.9), decreasing temperature from $T_{\text {dep }}=723 \mathrm{~K}$ to $\mathrm{T}_{\text {dep }}=573 \mathrm{~K}$ in steps of $15 \mathrm{~K}$ (branch II in Fig.9), increasing temperature from $T_{\text {dep }}=573 \mathrm{~K}$ to $T_{\text {dep }}=723 \mathrm{~K}$

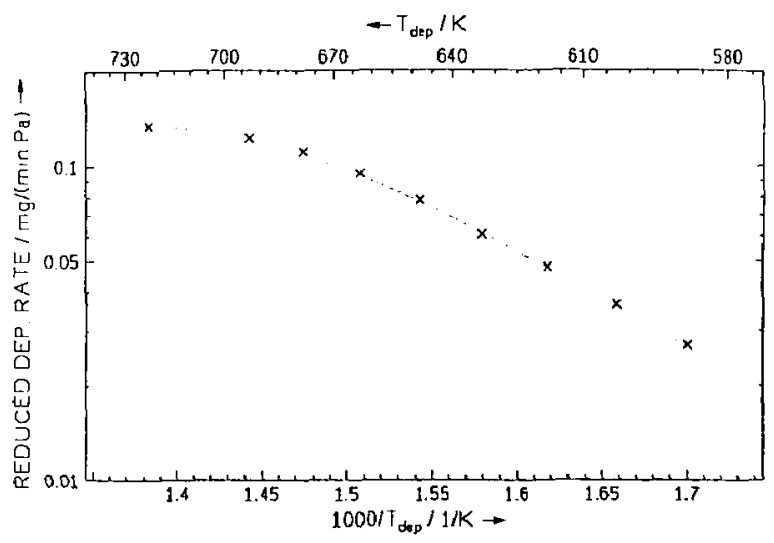

Fig. 7. Reduced deposition rate on a platinum precoated substrate $\left(T_{p r e}=723 \mathrm{~K}\right)$ vs. reciprocal temperature $\left(p_{\text {total }}=\right.$ $1000 \mathrm{~Pa}$ )

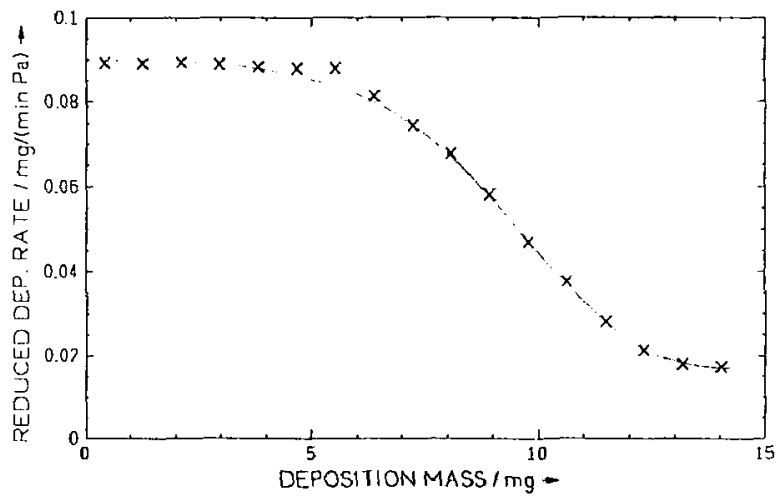

Fig. 8. Reduced deposition rate at $T_{\text {dep }}=653 \mathrm{~K}$ on a platinum precoated substrate $\left(\mathrm{T}_{\text {pre }}=723 \mathrm{~K}\right)$ vs. succeeding deposition mass $\left(p_{\text {total }}=1000 \mathrm{~Pa}\right)$

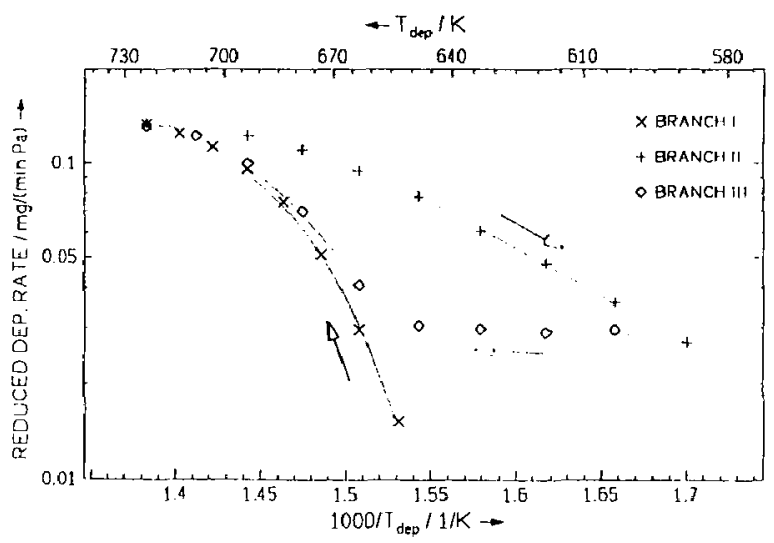

Fig. 9. Reduced deposition rate on platinum precoated substrates vs. reciprocal temperature $\left(p_{[t(n)}=1000 \mathrm{~Pa}\right)$ 
in steps of $15 \mathrm{~K}$ (branch III in Fig.9). Branch I of the plot corresponds to the normal Arrhenius plot depicted in Fig.6 and branch II corresponds to Fig.7. The horizontal part of branch III resulted from two contrary effects: The deposition rate decreases because of the reduced influence of the precoating at higher temperature (Fig.8) and at the same time the deposition rate increases because of increasing temperature. This yields a branch with almost constant deposition rates. Before reaching branch I the influence of the precoating disappears.

To prove the influence of the precoating deposition temperature on succeeding deposition rates, an experiment was carried out with an alternating temperature sequence (Fig. 10). The temperature was increased in steps of $10 \mathrm{~K}$ from $T_{\text {dep }}=653 \mathrm{~K}$ to $T_{\text {dep }}=723$ $\mathrm{K}$, with a measurement at $\mathrm{T}_{\mathrm{dep}}=653 \mathrm{~K}$ after each step. Fig. 10 shows, that the deposition process was influenced by precoated platinum films, if they were deposited at $T_{\text {pre }}>T_{\text {dep }}$. The deposition rates measured at a temperature of $T_{\text {dep }}=653 \mathrm{~K}$ (circles in Fig. 10) increased with increasing precoating temperature. Layers deposited at lower temperatures had no significant influence on the following deposition at higher temperatures. The rates symbolized with crosses in Fig. 10 correspond to Fig. 6.

The last measurement at $\mathrm{T}_{\mathrm{dep}}=653 \mathrm{~K}$ (indicated by an arrow in Fig. 10) was recorded after a precoating at $T_{\text {pre }}=723 \mathrm{~K}$. The observed rate corresponds to the rate depicted in Fig.7. This shows, that at the given deposition conditions and temperatures between $653 \mathrm{~K}$ and $723 \mathrm{~K}$ only deposition rates between branch I and branch II (Fig.9) can be achieved.

\subsection{Deposition of $\mathrm{Pt}(\mathrm{acac})_{2}$ in argon/oxygen-atmosphere}

The deposition of platinum from $\mathrm{Pt}(\mathrm{acac})_{2}$ was examined by adding oxygen during the deposition process to yield carbon free platinum films.

Before the deposition started, we observed a delay time, in which the mass of the substrate did not increase. This phenomenon has already been described by Xue et al. [8], who called this delay "induction period". Its duration depends on the deposition temperature. Observed values for the "induction period" were 20 minutes at $T_{\text {dep }}=$ $598 \mathrm{~K}$ or 12 minutes at $T_{\text {dep }}=623 \mathrm{~K}$. After the "induction period" the deposition rate was constant and independent of deposition temperalure (Fig. 11). The lower limit for the deposition temperature was given by the temperature of the pipe connecting evaporator and deposition reactor. No activation energy could be measured.

\section{Film characterization}

Samples were prepared in argon-atmosphere at a total gas pressure of $1000 \mathrm{~Pa}$ and temperatures of $\mathrm{T}_{\mathrm{dcp}}=653$ $\mathrm{K}, \mathrm{T}_{\mathrm{dcp}}=673 \mathrm{~K}, \mathrm{~T}_{\mathrm{dep}}=703 \mathrm{~K}$ and $\mathrm{T}_{\mathrm{dep}}=723 \mathrm{~K}$. Additionally one substrate coated at an oxygen partial pressure 
of $29 \mathrm{~Pa}$ was studied. The color of the platinum layers coated in argon-atmosphere varied from silver-grey ( $\mathrm{T}_{\text {dep }}$ $=6.53 \mathrm{~K})$ to black ( $T_{\text {dep }}=723 \mathrm{~K}$ ). The films prepaued in argon/oxygen-atmosphere were always silver-colored.

\subsection{Film composition}

The composition of the platinum films was examined with WDX-analysis. The films deposited in argonatmosphere consisted of platinum and carbon. The relative amount of carbon increased with increasing deposition tenperature. The plat inum layer deposiled by addling oxygen contained no carbon. Table 1 shows the count rales of the WDX-detector.

To determine the absolute amount of carbon contamination the carbon was completely removed with an oxidizing flame and the weight decrease was measured. The molar ratio between carbon and platinum was among 1.9:1 at $T_{\mathrm{dep}}=653 \mathrm{~K}$ and $2.4: 1$ at $T_{\text {dep }}=723 \mathrm{~K}$. The large amount of carbon corresponds to the results reported by Goto et al. [7] or Rand [3].

Table 1. WDX analysis of platinum coated aluminia substrates

\begin{tabular}{|ccccc|}
\hline $\mathrm{T}_{\text {den }}$ & attmosphere & intensity $\mathrm{Pl}$ & intensity C & $\begin{array}{c}\text { Pt-counts/ } \\
\text { C-counts }\end{array}$ \\
\hline $\mathrm{K}]$ & & [counts/sec] & [counts/sec] & \\
\hline 653 & $\mathrm{Ar}$ & 2209 & 300 & 7.4 \\
673 & $\mathrm{Ar}$ & 2240 & 370 & 6.0 \\
703 & $\mathrm{Ar}$ & 2450 & 416 & 5.9 \\
723 & $\mathrm{Ar}$ & 2450 & 440 & 5.6 \\
618 & $\mathrm{Ar} / \mathrm{O}_{2}$ & 2987 & 23 & 130 \\
\hline
\end{tabular}

\subsection{Surface texture}

The platinum films prepared in argon-atmosphere were studied with SEM and AFM. Fig. 12 shows the surface texture by SEM observation and Fig. 13 shows the surface texture by AFM observation. The grain sizes obtained by $A F M$-investigations are between $50 \mathrm{~nm}$ and $210 \mathrm{~nm}$. Our SEM and AFM studies gave no indications for phenomenon of different deposition rates described above. Fig. 14 presents a SEM-picture showing the porous structure of a platinum film deposited in argon/oxygen-atmosphere

\subsection{Film structure}

The structure of the films prepared in argon- and argon/oxygen-atmosphere was examined with XRD (Fig. 15 and Fig.16). In both cases the position and intensity of the XRD-peaks corresponded to the

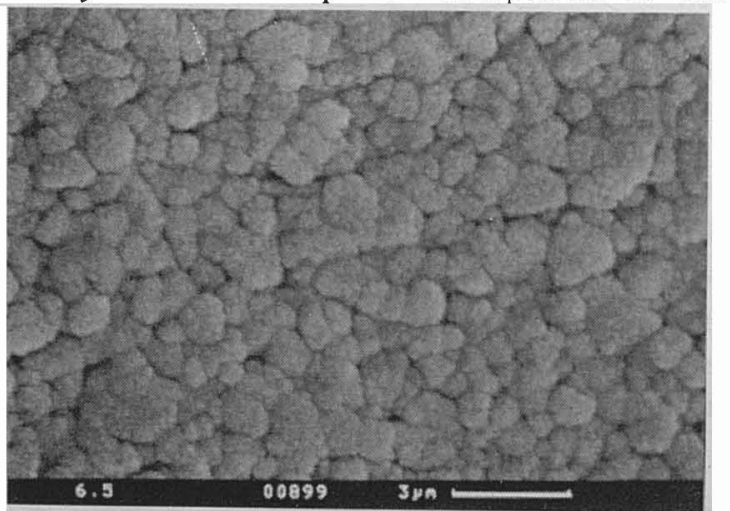

Fig. 12. SEM-picture of a platinum layer deposited in argnn-atmosphere $\left(T_{d c b}=70.3 \mathrm{~K}, p_{(0) a t}=100() \mathrm{Pa}\right)$

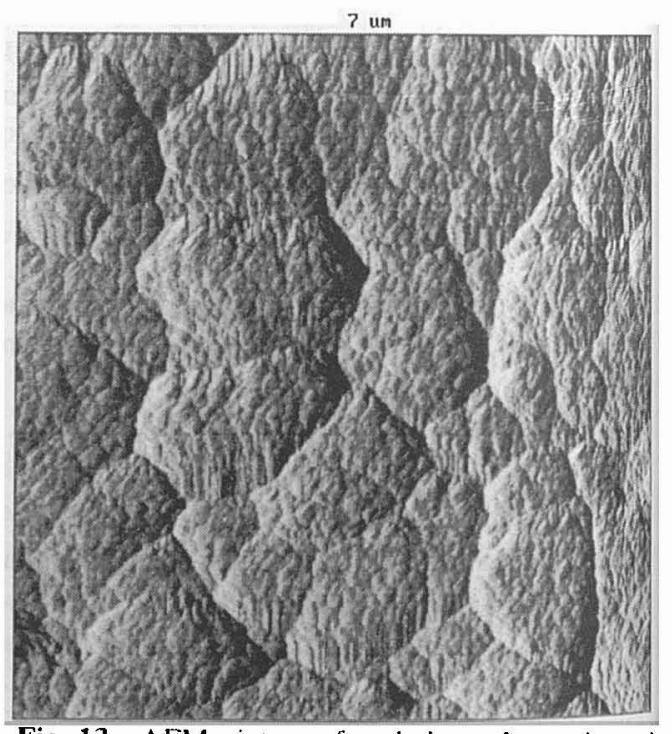

Fig. 13. AFM-picture of a platinum layer cleposited in argon-atmosphere $\left(\mathrm{T}_{\mathrm{dep}}=6.53 \mathrm{~K}\right.$, p total $\left.=100\right)$ l'a) 
structure of polycrystalline platinum [9]. The XIRD patterns of substrates coated at different deposition temperatures show no remiakable differences.

As Golo et al. [7] remarked, the distinguishing fealure of the films deposited in different atmospheres is the full widh at half maximum (FWHM) (argon-atmosphere: $2.56^{\circ}$, argon/oxygen-atmosphere: $0.29^{\circ}$ ). In the case of carton contminated films, the XRD-signals are very broad, which could be explained in principle either by small grain sizes or a distorted lattice structure. According to the grain size observed by AFM it seems reasonable that the broad signals are caused by carbon induced lattice distortion. This is confirmed by yielding slarp XRD-reflexes after burning off the carbon content. Our XRD-investigations could not clarify the phenomenon of the different deposition rates either.

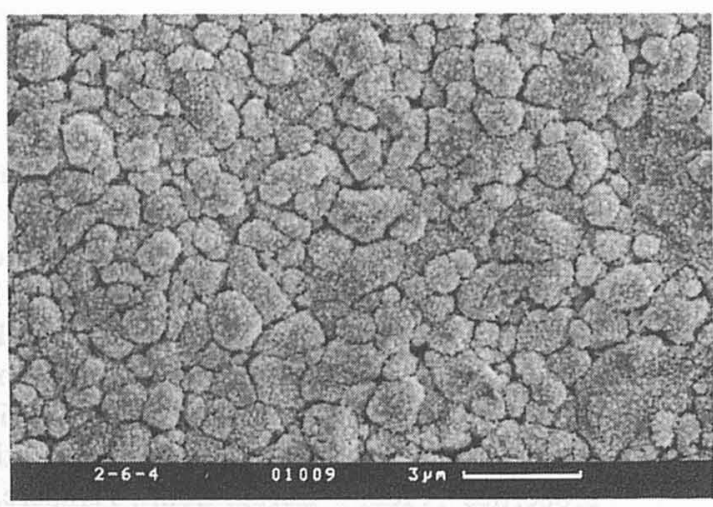

Fig. 14. SEM-picture of a platinum layer deposited in argon/oxygen-atmosphere $\left(\mathrm{T}_{\mathrm{dcp}}=618 \mathrm{~K}, \mathrm{p}_{\mathrm{trtal}}=\right.$ $1000 \mathrm{~Pa}, \mathrm{p}_{\text {oxyecn }}=29 \mathrm{~Pa}$ )

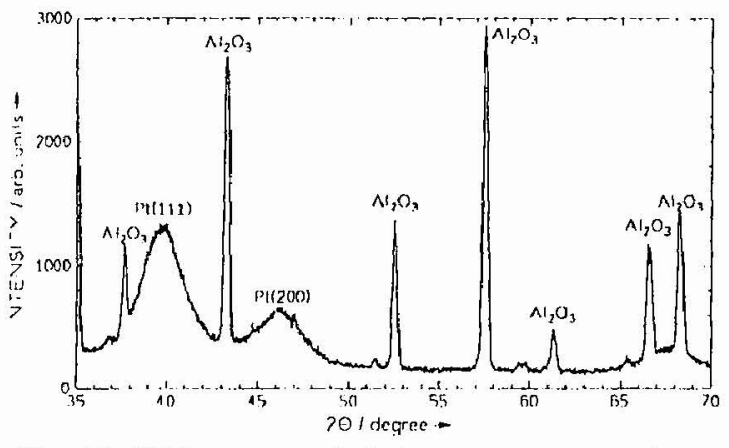

Fig. 15. XRD-pattern of platimum covered alumina substrate (argon-atmosphere, $\mathrm{p}_{1 \text { (nil }}=1000 \mathrm{~Pa}, \mathrm{~T}_{\mathrm{dep}}=$ $723 \mathrm{~K}$ )

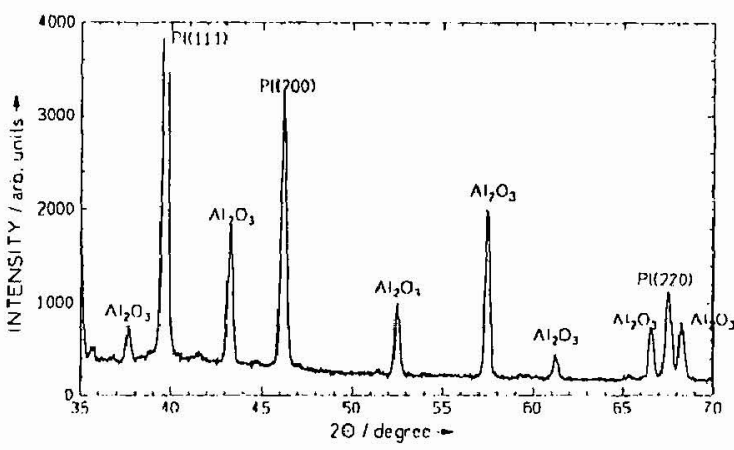

Fig. 16. XRD-pattern of platinum covered alumina substrate (argon/oxygen-atmosphere, $p_{\text {total }}=1000$ $\mathrm{Pa}, \mathrm{p}_{\text {oxyzen }}=29 \mathrm{~Pa}, \mathrm{~T}_{\text {dep }}=618 \mathrm{~K}$ )

\section{Conclusion}

The evaporation and deposition of $\mathrm{Pt}(\mathrm{acac})_{2}$ have been investigated. The activation energy for evaporation was determined to be $113 \pm 5 \mathrm{~kJ} / \mathrm{mol}$.

The decomposition reaction of $\mathrm{Pt}(\mathrm{acac})_{2}$ was strongly influenced by the pretreatment of the substrates. In argonatnosphere we obtained an activation energy of $204 \pm 9 \mathrm{~kJ} / \mathrm{mol}$ by starting deposition at low temperatures. Additionally, we yielded an activation energy of $56 \pm 1 \mathrm{~kJ} / \mathrm{mol}$ for deposition on a platinum covered substrate precoated at $T_{\text {pre }}=723 \mathrm{~K}$, which demonstrates the strong influence of the substrate. Our investigations showed that only platinum layers deposited at temperatures $T_{\text {pre }}>T_{\text {dep }}$ influence the deposition process. This effect disappeared, if a precoated substrate was coated at $T_{d e n}=$ const. for a long deposition time. Further research is required in order to explain this effect.

In argon/oxygen-atmosphere no activation energy could be measured. The platinum layers prepared in argon had a high amount of carbon contamination. Adding oxygen during the deposition yielded carbon free platinum layers. 


\section{References}

[1] Chem, N.J., Kaesz, H.D., Thridandam, H., R.F. Hicks, Appl. Phys. Lett., 53 (1988) 1591.

[2] Marboe E.C., U.S.Pat. $2430520,1947$.

[3] Rand M.J., J. Electrochem. Soc., 120 (1973) 686 - 692.

[4] Pulver M., Wahl G., Scheyett H. and Sommer M., "Deposition of $\mathrm{ZrO}_{2}$ and $\mathrm{Y}_{2} \mathrm{O}_{3}$-stabilized $\mathrm{ZrO}_{2}$ from $\beta$-diketonates", Proc. $9^{\text {th }}$ Europ. Conf., Tampere, Finland, 1993, ed by T. Mäntylä. (Supplément au Journal de Physique II, Volume 3, aout 1993) pp 305 - 310.

[5] Decker W., Nürnberg A., Pulver M., Stolle R., Wahl G., Erokhin Y.Y., Gorbenko O.Y., Graboy I.E., Kaul A.R., Sommer M., Vogt U., "CVD of high $T_{\mathbf{c}}$-Superconductors", Proc. $12^{\text {th }}$ Int. Conf. CVD, ed by K.F.Jensen and G.W.Cullen Honululu, 1993, pp $265-272$.

[6] Wahl G., Thin solid films, 40 (1976) $13-26$.

[7] Goto, T.; Vargas and R.; Hirai, T, "Preperation of iridium and platinum films by MOCVD and their properties", Proc. $9^{\text {th }}$ Europ. Conf., Tampere, Finland, 1993, ed by T. Mäntylä. (Supplément au Journal de Physique II, Volume 3, aout 1993) pp 297 - 304.

[8] Xue. Z.; Thridandam H.; Kaesz H.D.and Hicks, R.F., Chem. Mater., 4 (1992) 162 - 166.

[9] JCPDS, Metals \& Alloys Data Book, Vol. I, 1978, p 84. 